\title{
Factors influencing persistence of Legionella pneumophila serogroup 1 in laboratory cocultures
}

\author{
Angelo G Solimini, Alessia Cottarelli, Lucia Marinelli and Maria De Giusti
}

\begin{abstract}
Background: Risk for infections from Legionella pneumophila for immunocompromised individuals increases greatly when this species is present within the biofilm of the water distribution systems of hospitals or other health facilities. Multiplication and persistence of Legionella may dependent also upon planktonic growth in alternative to sessile growth. Here we compared the persistence of L. pneumophila serogroup 1 in experimental planktonic co-cultures subsided with iron, Pseudomonas aeruginosa and other non Legionella bacteria (quantified as Heterotrophic Plate Count, $\mathrm{HPC}$ at $37^{\circ} \mathrm{C}$ ), isolated from drinking water sources of a large hospital.

Results: Concentrations of L. pneumophila showed a decreasing pattern with incubation time in all co-cultures, the degree of reduction depending on the experimental treatment. In co-cultures with added $P$. aeruginosa, no L. pneumophila was detectable already after 4 days of incubation. In contrast in co-cultures without $P$. aeruginosa, HPC but not iron were significant factors in explaining the pattern of L. pneumophila, although the HPC effect was different according to the incubation time (HPC $x$ time interaction, $p<0.01$ ).

Conclusions: Our results highlight the need of controlling for both HPC and metal constituents of the water systems of buildings used by individuals at particular risk to the effects of Legionella exposure.
\end{abstract}

Keywords: Legionella pneumophila, Pseudomonas aeruginosa, Biofilm, Planktonic phase, Heterotrophic plate count, Drinking water, Hospital, Iron

\section{Background}

Legionella pneumophila is an ubiquitous microorganism present in both natural and artificial water systems that may cause a potential life threatening form of pneumonia called Legionnaires' disease. Especially when colonizing the water distribution systems of buildings of hospitals or other health facilities, the risk for infections for immunocompromised individuals increases greatly. In such artificial aquatic systems, the biofilm covering the interior of pipelines and, more in general, the various plumbing elements represent relatively nutrient-rich spots where Legionella (and other bacteria) can attach and multiply $[1,2]$. Biofilm is a matrix composed by heterogeneous aggregates of bacteria, fungi, protozoa, and algae embedded into extracellular polymeric substances [3]. As a result, many engineered water systems such as air conditioning cooling towers, water boilers, whirlpools and spas, drinking water distribution networks, shower heads, and dental-unit

\footnotetext{
*Correspondence: angelo.solimini@uniroma1.it

Department of Public Health and Infectious Diseases, Sapienza University of Rome, Piazza A. Moro 5, 00185 Rome, Italy
}

water lines provide an environment conducive to the growth and multiplication of Legionella species ([2] and references therein).

The survival of microorganisms in man-made systems results from the (interactive) effects of several factors which depend themselves from the structure and management of the water network. Those factors include temperature [4], pipe material [5], nutrient levels [6-8], frequencies, type and concentration of disinfectants $[9,10]$, water velocity [11] and hydraulic conditions [12]. Among the micronutrients, lower levels of certain metals enhance growth of L. pneumophila [13] and especially iron has been linked to L. pneumophila extracellular growth, intracellular replication, and virulence [14,15]. As iron availability in water distribution systems may be linked with the older age and metal constituents of pipes [13], corrosion products are important factors in the survival and growth of L. pneumophila in artificial habitats $[13,16]$.

Several empirical environmental studies have examined the simultaneous effects of chemical elements, biofilm biomass (also quantified as heterotrophic plate counts, HPC, 
at $22^{\circ} \mathrm{C}$ and $/$ or $37^{\circ} \mathrm{C}$ ) and other factors on L. pneumophila presence [17-19] with inconsistent results [20,21]. For example, occurrence of Legionella spp in samples from public and private structures (including hospitals, hotels and private houses) was positively associated with $\mathrm{HPC}$ at $22^{\circ} \mathrm{C}$ (but not with $\mathrm{HPC} 37^{\circ} \mathrm{C}$ ), manganese (but not iron) and negatively with copper and higher water temperatures [22].

In experimental cocultures the growth and/or persistence of L. pneumophila was positively associated with several isolates of heterotrophic bacteria from potable water [23-26] as well as negatively with others, that were able to inhibit Legionella growth [27-29]. In particular, P. aerugi$n o s a$, another species often present in artificial water systems, seems able to secrete inhibitory substances like lactones [30] and resulted not conductive to L. pneumophila [26].

More generally, Legionella persistence in artificial systems was linked to its capacity of parasitize several species of protozoans and to multiply within them [2], to efficiently exploit available nutrients from the surroundings [2], and to obtain nutrients with necrotrophic feeding [31]. It has been suggested that multiplication of Legionella may dependent upon planktonic growth in alternative to sessile growth (e.g. within biofilm), because the planktonic phase would increase the likelihood of protozoan encounters [32]. If Legionella can persist in a planktonic phase also in absence of protozoans remains unclear, and this information is relevant for adopting the necessary management strategies in water systems where the presence of $L$. pneumophila increases the infection risk.

The aim of this study is to test the persistence of L. pneumophila in experimental planktonic cocultures subsided with iron, $P$. aeruginosa and other non Legionella bacteria (quantified as $\mathrm{HPC}$ at $37^{\circ} \mathrm{C}$ ) isolated from the drinking water of a large hospital. In this system, despite the risk management interventions with regular disinfections, L. pneumophila has been isolated several times at several water point of use in the past few years [33].

\section{Methods}

\section{Study design}

To test the effect of subsidy of iron, other non Legionella bacteria (measured as $\mathrm{HPC}$ at $37^{\circ} \mathrm{C}$ ) and $P$. aeruginosa copresence on $L$. pneumophila, we set up a full factorial design with iron (2 levels: 0 and $0.1 \mathrm{mg} / \mathrm{l}$ initial concentrations), $\mathrm{HPC}$ at $37^{\circ} \mathrm{C}$ (3 levels: 0,10 and $100 \mathrm{CFU} / \mathrm{ml}$ initial concentrations) and $P$. aeruginosa (2 levels: 0 and $10 \mathrm{CFU} / \mathrm{ml}$ initial concentrations) as factors. All factor level combinations were prepared in duplicate samples. A total of 24 tubes were generated (see below preparation of co-cultures) inoculating a fixed concentration of L. pneumophila in each test tube and measuring its density over four time points (at $0,4,8,16$ days from inoculum) as described below.

\section{Bacterial strains}

The Legionella strain used in this study was a control strain of L. pneumphila serogroup 1 (American Type Culture Collection,ATCC, 33152, Oxoid Ltd., UK). This strain was used because the same serogroup was isolated from the tap water of the hospital where the other bacteria were also obtained. This strain was grown in Buffered Charcoal Yeast Extract (BCYE) agar supplemented with L-cysteine (SR110C Oxoid), Ferric pyrophosphate $0,25 \mathrm{~g} / \mathrm{L}$ and selective antibiotics (Polymyxin B, Anisomycin and Vancomycin; SR0118E Oxoid) incubated at $36 \pm 1^{\circ} \mathrm{C}$ with $2.5 \% \mathrm{CO}_{2}$ for 10 days.

The bacteria used in co-cultures were isolated from tap water of the hospital according to the standard method (UNI EN ISO 6222:2001). The following species were isolated, identified (Vitek 2 Compact bioMerieux) and maintained in monospecific colonies on a Standard Plate Count agar (Oxoid): Brevundimonas diminuta/vescicularis, Sphingomonas paucimobilis, Acinetobacter baumanni, Pseudomonas alcaligenes. P. aeruginosa was isolated from the tap water of a different point of use of the hospital according to the standard UNI EN 12780:2002 and maintained on Pseudomonas agar base (CM0559, Oxoid) with selective supplement (SR0103E, Oxoid).

\section{Preparation of co-cultures}

A single colony of L. pneumophila was transferred in $100 \mathrm{ml}$ of buffered yeast extract broth (yeast extract: $10 \mathrm{~g} / \mathrm{L}$; glicine: $3 \mathrm{~g} / \mathrm{L}$ ) supplemented with L-cysteine (SR110C) and incubated overnight at $36 \pm 1^{\circ} \mathrm{C}$ with constant shaking [30].

Before the inoculum, the optical density (OD) was measured at $600 \mathrm{~nm}$ (OD600; Coulter Du-530, Beckman) to determine the concentration of bacteria in $1 \mathrm{ml}$ of suspension. The concentration of Legionella in the suspension was then adjusted till an OD600 of 0.19 by adding fresh buffered yeast extract broth.

A single colony of $P$. aeruginosa was transferred into $30 \mathrm{ml}$ of sterile physiological saline solution and incubated overnight at $36 \pm 1^{\circ} \mathrm{C}$ with constant shaking. The other biofilm components (HPC) were similarly incubated by transferring a single colony from each monospecific culture in $30 \mathrm{ml}$ of steril physiological saline solution. The concentrations of $P$. aeruginosa and of HPC were determined similarly to L. pneumophila by measuring OD600 and adjusting the concentration in the suspensions using predetermined relationships between OD600 and viable counts.

Co-cultures were set up according to the study design by adding $1 \mathrm{ml}$ of $L$. pneumophila suspension, $0.1 \mathrm{ml}$ of $\mathrm{HPC}$ and $0.1 \mathrm{ml}$ of $P$. aeruginosa and iron $(0.1 \mathrm{mg} / \mathrm{L}$, added as ferrous sulfate eptaidrate (Cpachem), to $9 \mathrm{ml}$ of sterile deionized water with resistivity $18,2 \mathrm{M} \Omega \times \mathrm{cm}$ and conductivity $0,055 \mu \mathrm{S} / \mathrm{cm}$ a $25^{\circ} \mathrm{C}$ and left in the dark at room temperature (approximately $23^{\circ} \mathrm{C}$ ). 


\section{Cells enumeration}

All the microbial parameters in each different co-culture were monitored at different times in accordance to the study design (at 0, 4, 8, 16 days from inoculum), to determine the variation of concentration by the viable count method on selective agar.

Concentration of $L$. pneumophila was determined by seeding serial dilutions of $0.1 \mathrm{ml}$ from each co-culture on the selective agar $\mathrm{BCYE}$ supplemented with L-cysteine. The plates in duplicate were incubated at $36 \pm 1^{\circ} \mathrm{C}$ with $2.5 \% \mathrm{CO}_{2}$ for 10 days and the reading was performed at intervals of 2-3 days. The detection limit of this method was $10 \mathrm{CFU} / \mathrm{ml}$.

HPC concentration was determined by the inclusion method by seeding serial dilutions of $1 \mathrm{ml}$ of the microcosm solution on Stadard Plate Count Agar and incubated at $36 \pm 2{ }^{\circ} \mathrm{C}$ for 48 hours. The concentration of $P$. aeruginosa was determined by seeding serial dilutions of $0.1 \mathrm{ml}$ of the microcosm on Pseudomonas agar base with supplement and incubated $36 \pm 2^{\circ} \mathrm{C}$ for 48 hours.

\section{Statistical analysis}

Differences in HPC and P. aeruginosa ( $\log _{10}$ transformed) concentrations between subsidised co-cultures controls at each time from inoculum were assessed with an Anova and subsequent multiple comparisons with Bonferroni correction. Pattern of Legionella concentration ( $\log _{10}$ transformed) between different treatments over the 4 times was modelled using a linear model for correlated data [34]. Time from inoculum, iron, HPC were entered as fixed effects and all second and third order interactions tested. A heterogeneous variance-covariance structure was used to account for non homogenous variances in ( $\log _{10}$ transformed) L. pneumophila concentration between times. Additionally, autoregressive error structure was used to handle correlated errors deriving from the repeated measures design [34]. The model with heterogeneous variance covariance structure and autoregressive errors was preferred over simpler models (with homogeneous variance and/or no autoregressive errors) after model comparisons using AIC and likelihood test [34]. All analysis was carried out using R 3.0.2 and packages nlme 3.1 [35] and lsmeans 2.05 [36].

\section{Results}

$P$. aeruginosa and HPC concentrations (Table 1 ) were different between treatments and controls at time 0 , according to the experimental design (Anova, all comparisons at time $0, \mathrm{p}<0.05$ ). After 4 days of incubation, the mean concentrations of HPC and $P$. aeruginosa in co-cultures with L. pneumophila reached concentrations $>1 \times 10^{6} \mathrm{CFU} / \mathrm{ml}$ and increased reaching concentrations $>1 \times 10^{8} \mathrm{CFU} /$ $\mathrm{ml}$ at 16 days of incubation, being similar in all experimental treatments (Anova, all comparisons at times 4, $8,16, \mathrm{p}>0.05)$.
Concentrations of L. pneumophila showed a decreasing pattern with incubation time in all co-cultures (Figure 1 and 2), the degree of reduction in concentrations depending on the experimental treatment. In the co-cultures with added $P$. aeruginosa, at time $0 L$. pneumophila concentrations were not different between co-cultures supplemented with different initial iron $(\mathrm{p}=0.10)$ and HPC concentrations $(\mathrm{p}=0.15)$ but no L. pneumophila was detectable already after 4 days of incubation (Figure 2). In contrast, in co-cultures without $P$. aeruginosa (Figure 1), HPC but not iron treatments were significant factors in explaining the pattern of L. pneumophila (Table 2). The HPC effect was different according to the incubation time (HPC $\times$ time factor, $\mathrm{p}<0.01$, Table 2). After 4 days of incubation, L. pneumophila concentrations were higher than controls only in co-cultures supplemented with HPC at initial concentration of $100 \mathrm{CFU} / \mathrm{ml}$ (Table 3, mean difference $=-0.39 \mathrm{CFU} / \mathrm{ml}, \mathrm{p}<0.05)$ while starting from day $8 \mathrm{~L}$. pneumophila concentration was higher than controls in all HPC level treatments (Table 3, all differences $\mathrm{p}<0.05$ ).

\section{Discussion}

Our results show a positive association between $L$. pneumophila concentration and the supplementation of HPC and iron and a negative association with $P$. aeruginosa presence. The main reason of this positive association is probably the fact that bacteria of the genus Legionella depends on other microbes to survive in nutrient poor environments such as the experimental planktonic cocultures. In water distribution systems and other manmade aquatic systems, Legionella interacts with other microrganisms by adopting several survival strategies $[17,37]$. The primary survival strategy is linked to Legionella ability of deriving the necessary nutrients (carbon, nitrogen, and amino acids) from dead microrganisms (via necrophilic exploitation, [31]) or by efficient uptake of nutrients excreted by other bacteria [2]. Second, Legionella is also able to parasitize a wide range of protozoans and to multiply within them $[2,38]$. The same capacity is shown when Legionella infects alveolar macrophages of humans, causing pulmonary infections. Third, Legionella seems also able to enter a planktonic growth phase (opposed to the benthonic attached phase), in response to low nutrient conditions within the biofilm [2]. Additionally, biofilm embedded Legionella cells may have enhanced protection from chlorine based biocides that are commonly used to manage the infection risks in private and public buildings $[1,18,39]$.

In our experiment, Legionella was able to persist in planktonic cultures supplemented with HPC but not in those supplemented with iron alone or with $P$. aeruginosa (regardless co-presence of iron and/or HPC). Therefore, although iron has been linked to $L$. pneumophila 
Table 1 Average concentrations ( $\log _{10}$ transformed) and standard error (SE) of heterotrophic plate count (HPC) and $P$. aeruginosa at different times from inoculum in cocultures with $L$. pneumophila srg 1 with different treatment Co-culture initial condition

P. aeruginosa (CFU/ml)

$\mathrm{Fe}(\mathrm{mg} / \mathrm{l})$

HPC (CFU/ml)

Time from

inoculum (day)

HPC $\log _{10}$

P.aeruginosa

(CFU/ml) (SE)

$\log _{10}(\mathrm{CFU} / \mathrm{ml})$ (SE)

0

0

0

0

0

10

10

10

10
$0 \quad 0$

4

8

16

0.1

0

10

0.1

10

0

100

0.

100

0

0

0.

0

10

0

100

0

0

0

0

0

0

0

$1.6(0.2)$

$6.0(0.0)$

$8.0(0.1)$

$7.5(0.1)$

$2.0(0.2)$

$6.0(0.0)$

$8.1(0.1)$

$$
8.3(0.1)
$$

$3.0(0.0)$

$6.0(0.0)$

$8.9(0.0)$

$8.5(0.0)$

$3.0(0.0)$

$6.0(0.0)$

$8.3(0.1)$

$8.2(0.1)$

0

$1.3(0.0)$

$8.3(0.0)$

$8.7(0.0)$

$8.2(0.0)$

$1.7(0.0)$

$8.3(0.0)$

$8.5(0.0)$

$8.9(0.0)$

$2.0(0.2)$

$1.2(0.0)$

$6.0(0.0)$

$8.3(0.0)$

$8.5(0.0)$

$8.5(0.0)$

$8.3(0.0)$

$8.3(0.0)$

$3.2(0.0)$

$1.7(0.0)$

$6.0(0.0)$

$8.3(0.0)$

$8.5(0.0)$

$8.5(0.0)$

$8.7(0.0)$ 
Table 1 Average concentrations ( $\log _{10}$ transformed) and standard error (SE) of heterotrophic plate count (HPC) and $P$. aeruginosa at different times from inoculum in cocultures with $L$. pneumophila srg 1 with different treatment (Continued)

\begin{tabular}{|c|c|c|c|c|c|}
\hline \multirow[t]{4}{*}{10} & 0.1 & 10 & 0 & $2.1(0.1)$ & $1.4(0.1)$ \\
\hline & & & 4 & $6.0(0.0)$ & $8.3(0.0)$ \\
\hline & & & 8 & $8.4(0.0)$ & $8.6(0.1)$ \\
\hline & & & 16 & $9.8(0.0)$ & $9.3(0.0)$ \\
\hline \multirow[t]{4}{*}{10} & 0.1 & 100 & 0 & $3.2(0.0)$ & $1.8(0.0)$ \\
\hline & & & 4 & $6.0(0.0)$ & $8.3(0.0)$ \\
\hline & & & 8 & $8.4(0.0)$ & $8.6(0.0)$ \\
\hline & & & 16 & $9.8(0.0)$ & $9.5(0.0)$ \\
\hline
\end{tabular}

extracellular growth, intracellular replication, and virulence $[14,15]$, it was unable to sustain L. pneumophila without the contemporary presence of other microrganisms, which were probably the source of other essential nutrients. This result is also coherent with the observation that supplemented iron increases Legionella persistence in HPC supplemented co-cultures beyond the levels reached in co-cultures with HPC only (Table 3). It has been previously shown that iron (but also other elements necessary for Legionella growth like other metals or nutrients like phosphorus) in bioavailable form can be released by certain pipe constituents via biofilm mediated corrosion or from deposits of materials in stagnant portions of the water distribution system [40,41]. Additionally, certain chemical compounds released from pipes can interfere with the chlorine based disinfectant decreasing its effects on biofilm cells $[42,43]$. Therefore, when managing Legionella risk, the effect of pipe material and the physical structure of the water distribution network should be taken into account.

In our co-cultures the presence of $P$. aeruginosa, regardless of the level of supplements HPC and iron inhibited
L. pneumophila growth from the early beginning of the experiments. This inhibitory effect on Legionella growth has been shown for several microrganisms residing in the same biofilm matrix. For example, [29] suggested that up to $32 \%$ of HPC bacteria (including Aeromonas, Vibrio, Pseudomonas and Pseudomonas-like strains) isolated from chlorinated drinking water were able of inhibiting or slowing the growth of Legionella species. Another study showed that L. pneumophila cannot attach in biofilms with preexistent $P$. aeruginosa [26]. Although many mechanisms involved in the processes of microbial interference are only partially known [17], the production of inhibitory bacteriocins was linked to Legionella growth suppression in several earlier studies. For example, [28] showed that a bacteriocin producer like $P$. fluorescens, can inhibit both the formation and the stability of L. pneumophila biofilms. Similarly, it has been shown that Legionella can attach to P. aeruginosa monospecies biofilms but cannot persist for more than 2 days of incubation [26], possibly because of the effect of homoserine lactones produced by $P$. aeruginosa [30]. It remains to be clarified if Legionella can persist in viable but
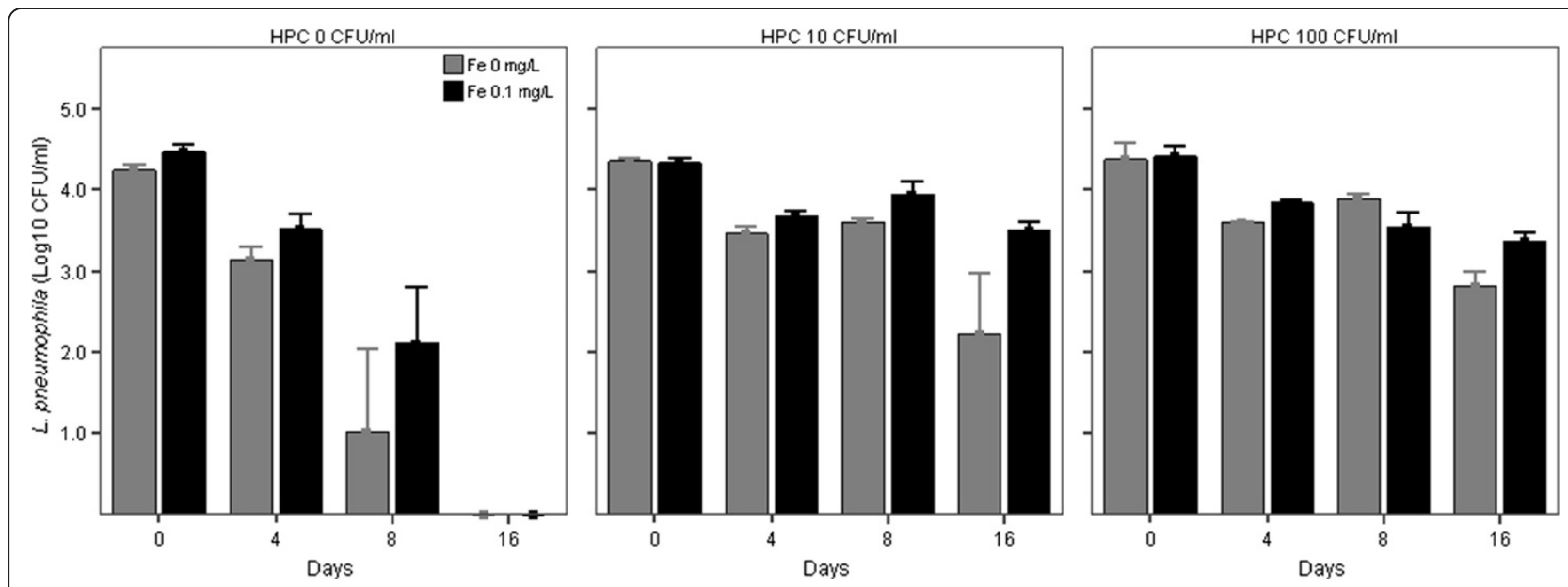

Figure 1 Persistence of $L$. pneumophila srg 1 in co-cultures with different initial heterotrophic plate counts at $37^{\circ} \mathrm{C}(\mathrm{HPC})$ and iron (Fe) subsidy in absence of $P$. aeruginosa. Bars show mean and 1 standard error. 

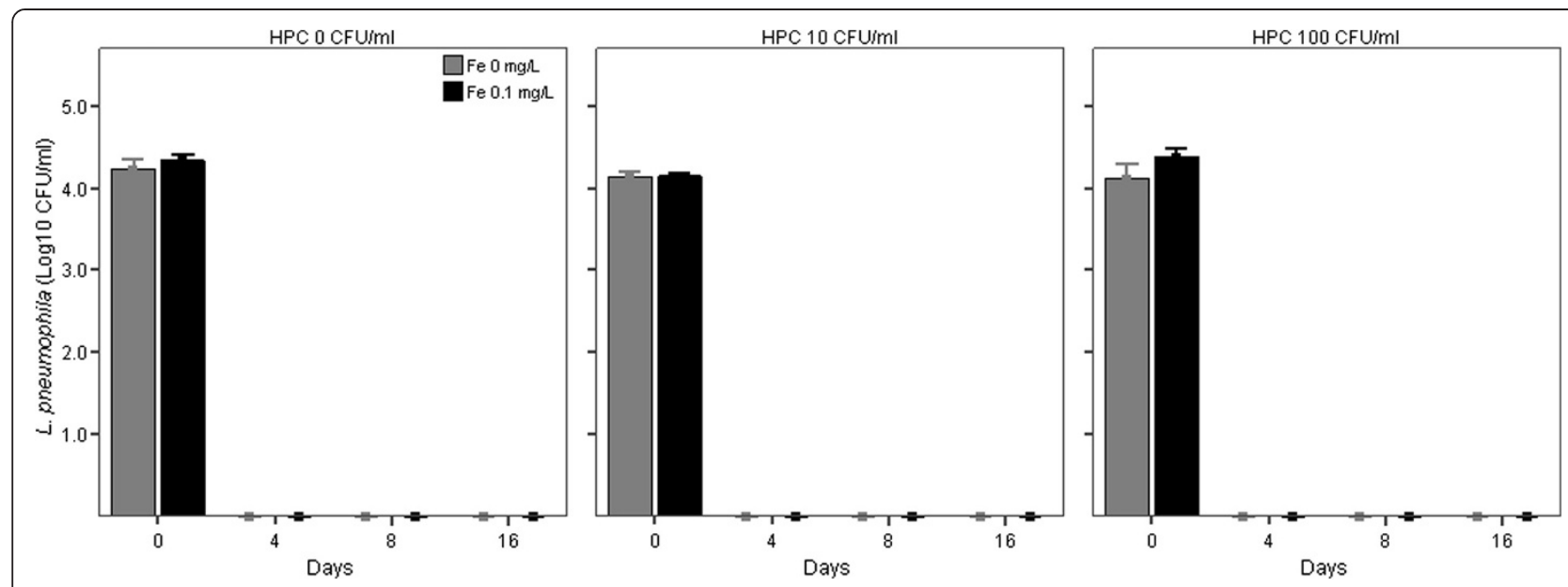

Figure 2 Persistence of $L$. pneumophila srg 1 in co-cultures with different initial heterotrophic plate counts at $37^{\circ} \mathrm{C}(\mathrm{HPC})$ and iron (Fe) in presence of $P$. aeruginosa. Bars show mean and 1 standard error.

not cultivable form (VBNC, a form still able to cause human infections, [44]) even in presence $P$. aeruginosa. This may explain the reason why we found positive samples to Legionella $\mathrm{VBNC}$ in a previous cross sectional survey of at point of use water sources in the same hospital from where the biofilm of this experiment was obtained.

\section{Conclusion}

Many studies examined so far the relative effect of several factors that are reported empirically to increase the likelihood of Legionella presence in water distribution systems in settings like hospitals or other health care facilities where a formal risk assessment and management is a priority [1]. The results of our experiments support those studies reporting a positive association with HPC counts and iron subsidy and a strong negative association with $P$. aeruginosa, also in static flow conditions. Notably, all the microbial colonies used in this study were previously isolated from the hospital drinking water

Table 2 Effect of experimental treatments on $\left(\log _{10}\right.$ transformed) L. pneumophilasrg 1 in cocultures without $P$. aeruginosa

\begin{tabular}{llll}
\hline Term & $\begin{array}{l}\text { Numerator degrees } \\
\text { of freedom }\end{array}$ & F statistics & P-value \\
\hline Intercept & 1 & 1136.11 & $<0.01$ \\
HPC & 2 & 0.36 & 0.70 \\
$\mathrm{Fe}$ & 1 & 2.21 & 0.14 \\
Time & 3 & 39.07 & $<0.01$ \\
Fe $\times$ HPC & 2 & 0.86 & 0.43 \\
HPC $\times$ time & 6 & 5.39 & $<0.01$ \\
Fe $\times$ time & 3 & 0.72 & 0.54 \\
Fe $\times$ HPC $\times$ time & 6 & 1.15 & 0.34 \\
\hline
\end{tabular}

Time: time from inoculum (4 levels: 0, 4, 8, 16 days), Fe: iron (2 levels: 0 and $0.1 \mathrm{mg} / \mathrm{L}$ initial concentrations), HPC: heterotrophic plate count (3 levels: 0,10 and $100 \mathrm{CFU} / \mathrm{ml}$ initial concentrations). at point of use, and our data provide specific insights for the management of Legionella risk in this hospital setting. Although a confirmatory study should be designed in microcosms with dynamic flow conditions, our results highlight the need of controlling for both HPC and metal constituents into water systems of buildings at particular risk for the effects of Legionella exposure on humans such as hospitals and care homes for the elderly. Future studies should also elucidate the effect of protozoans in modifying the persistence of L. pneumophila in co-cultures as well as in water distribution systems. Moreover, additional effort should also investigate what environmental factors of the drinking water systems trigger the entrance to and the exit from VBNC state (including escape strategy from repeated chlorination cycles [39]). This understanding could lead to improved control measures for L. pneumophila in hospital settings.

Table 3 Multiple pairwise comparisons of L. pneumophila srg 1 least squares means between co-cultures with different initial levels of heterotrophic plate count (HPC) and controls (no HPC added) at different times from inoculum

\begin{tabular}{lllll}
\hline $\begin{array}{l}\text { Time from } \\
\text { inoculum (day) }\end{array}$ & $\begin{array}{l}\text { Treatment } \\
\text { comparison } \\
\text { (HPC initial } \\
\text { concentrations; } \\
\text { CFU/ml) }\end{array}$ & $\begin{array}{l}\text { Mean difference } \\
\text { of marginal } \\
\text { means control - }\end{array}$ & $\begin{array}{l}\text { treatment } \\
\text { (standard error) }\end{array}$ & P-value \\
\hline 0 & $0-10$ & $0.01(0.10)$ & 0.08 & 0.99 \\
& $0-100$ & $-0.4(0.11)$ & -0.37 & 0.93 \\
4 & $0-10$ & $-0.24(0.12)$ & -2.00 & 0.12 \\
& $0-100$ & $-0.39(0.14)$ & -2.84 & 0.02 \\
8 & $0-10$ & $-2.21(0.39)$ & -5.68 & $<0.001$ \\
& $0-100$ & $-2.15(0.45)$ & -4.79 & $<0.001$ \\
16 & $0-10$ & $-2.86(0.34)$ & -8.52 & $<0.001$ \\
& $0-100$ & $-3.09(0.39)$ & -7.96 & $<0.001$ \\
\hline
\end{tabular}




\section{Competing interests}

The authors declare that they have no competing interests.

\section{Authors' contributions}

AS and LM conceived the study, AC and LM carried out the lab experiments, AS carried out the statistical analysis and wrote the first draft of the manuscript, AC, LM and MDG reviewed the manuscript, MDG supervised the whole study. All authors read and approved the final manuscript.

\section{Acknowledgements}

We thank Dr. F. Marzioni for assistance with iron addition.

Received: 23 May 2014 Accepted: 17 September 2014

Published online: 03 October 2014

\section{References}

1. Buse HY, Schoen ME, Ashbolt NJ: Legionellae in engineered systems and use of quantitative microbial risk assessment to predict exposure. Water Res 2012, 46:921-933.

2. Taylor M, Ross K, Bentham R: Legionella, protozoa, and biofilms: interactions within complex microbial systems. Microb Ecol 2009, 58:538-547.

3. Stoodley P, Sauer K, Davies DG, Costerton JW: Biofilms as complex differentiated communities. Annu Rev Microbiol 2002, 56:187-209.

4. Ndiongue S, Huck PM, Slawson RM: Effects of temperature and biodegradable organic matter on control of biofilms by free chlorine in a model drinking water distribution system. Water Res 2005, 39:953-964.

5. Moritz MM, Flemming H-C, Wingender J: Integration of Pseudomonas aeruginosa and Legionella pneumophila in drinking water biofilms grown on domestic plumbing materials. Int J Hyg Environ Health 2010, 213:190-197.

6. Miettinen IT, Vartiainen T, Martikainen PJ: Phosphorus and bacterial growth in drinking water. Appl Environ Microbiol 1997, 63:3242-3245.

7. Fang W, Hu JY, Ong SL: Influence of phosphorus on biofilm formation in model drinking water distribution systems. J Appl Microbiol 2009, 106:1328-1335.

8. Chu C, Lu C, Lee C: Effects of inorganic nutrients on the regrowth of heterotrophic bacteria in drinking water distribution systems. J Environ Manage 2005, 74:255-263.

9. Kim BR, Anderson JE, Mueller S, Gaines W, Kendall M: Literature review-efficacy of various disinfectants against Legionella in water systems. Water Res 2002, 36:4433-4444.

10. Butterfield PW, Camper AK, Ellis BD, Jones WL: Chlorination of model drinking water biofilm: implications for growth and organic carbon removal. Water Res 2002, 36:4391-4405.

11. Percival SL, Knapp JS, Wales DS, Edyvean RGJ: The effect of turbulent flow and surface roughness on biofilm formation in drinking water. $J$ Ind Microbiol Biotechnol 1999, 22:152-159.

12. Douterelo I, Sharpe RL, Boxall JB: Influence of hydraulic regimes on bacterial community structure and composition in an experimental drinking water distribution system. Water Res 2013, 47:503-516.

13. States SJ, Conley LF, Ceraso M, Stephenson TE, Randy S, Wadowsky RM, Mcnamara ANNM, Yee RB: Effects of metals on legionella pneumophila growth in drinking water plumbing systems. App/ Environ Microbio/ 1985 50:1149-1154.

14. Zheng $\mathrm{H}$, Chatfield $\mathrm{CH}$, Liles MR, Cianciotto NP: Secreted pyomelanin of legionella pneumophila promotes bacterial iron uptake and growth under iron-limiting conditions. Infect Immun 2013, 81:4182-4191.

15. Cianciotto NP: Iron acquisition by Legionella pneumophila. BioMetals 2007, 20:323-331.

16. Rakić A, Perić J, Foglar L: Influence of temperature, chlorine residual and heavy metals on the presence of Legionella pneumophila in hot water distribution systems. Ann Agric Environ Med 2012, 19:431-436.

17. Declerck P: Biofilms: the environmental playground of Legionella pneumophila. Environ Microbiol 2010, 12:557-566.

18. Berry $\mathrm{D}, \mathrm{Xi}$ C, Raskin L: Microbial ecology of drinking water distribution systems. Curr Opin Biotechnol 2006, 17:297-302.

19. Szewzyk U, Szewzyk R, Manz WSK-H: Microbiological safety of drinking water. Annu Rev Microbiol 2000, 54:81-127.
20. Mekkour M, Khalil E, Driss B, Tai J, Cohen N, De Microbiologie D, Environnement D, Pasteur I: Legionella pneumophila: an environmental organism and accidental pathogen. Int J Sci Technol 2013, 2:187-196.

21. Yamamoto $H$, Sugiura $M$, Kusunoki S: Factors stimulating propagation of legionellae in cooling tower water. App/ Environ Microbiol 1992, 58:1394-1397.

22. Bargellini A, Marchesi I, Righi E, Ferrari A, Cencetti S, Borella P, Rovesti S: Parameters predictive of Legionella contamination in hot water systems: association with trace elements and heterotrophic plate counts. Water Res 2011, 45:2315-2321.

23. Stout JE, Yu VL, Best MG: Ecology of Legionella pneumophila within water distribution systems. Appl Environ Microbiol 1985, 49:221-228.

24. Wadowsky R, Yee R: Effect of non-Legionel- laceae bacteria on the multiplication of Legionella pneumophila in potable water. Appl Environ Microbiol 1985, 49:1206-1210.

25. Edagawa A, Kimura A, Doi H, Tanaka H, Tomioka K, Sakabe K, Nakajima C, Suzuki Y: Detection of culturable and nonculturable Legionella species from hot water systems of public buildings in Japan. J Appl Microbiol 2008, 105:2104-2114.

26. Stewart CR, Muthye V, Cianciotto NP: Legionella pneumophila persists within biofilms formed by Klebsiella pneumoniae, Flavobacterium sp., and Pseudomonas fluorescens under dynamic flow conditions. PLoS One 2012, 7:e50560.

27. Gião MS, Azevedo NF, Wilks S, Vieira MJ, Keevil CW: Interaction of Legionella pneumophila and Helicobacter pylori with bacterial species isolated from drinking water biofilms. BMC Microbiol 2011, 11:57.

28. Guerrieri E, Bondi M, Sabia C, De Niederhäusern S, Borella P, Messi P: Effect of bacterial interference on biofilm development by Legionella pneumophila. Curr Microbiol 2008, 57:532-536.

29. Toze S, Sly L, MacRae I, Fuerst J: Inhibition of growth of legionella species by heterotrophic plate count bacteria isolated from chlorinated drinking water. Curr Microbiol 1990, 21:139-143.

30. Kimura S, Tateda K, Ishii Y, Horikawa M, Miyairi S, Gotoh N, Ishiguro M, Yamaguchi K: Pseudomonas aeruginosa Las quorum sensing autoinducer suppresses growth and biofilm production in Legionella species. Microbiology 2009, 155(Pt 6):1934-1939.

31. Temmerman R, Vervaeren H, Noseda B, Boon N, Verstraete W: Necrotrophic growth of Legionella pneumophila. Appl Environ Microbio/ 2006, 72:4323-4328

32. Mampel J, Spirig T, Weber SS, Janus AJ, Molin S, Hilbi H: Planktonic replication is essential for biofilm formation by legionella pneumophila in a complex medium under static and dynamic flow conditions. Appl Environ Microbiol 2006, 72:2885-2895.

33. Orsi GB, Vitali M, Marinelli L, Ciorba V, Tufi D, Del Cimmuto A, Ursillo P, Fabiani M, De Santis S, Protano C, Marzuillo C, De Giusti M: Legionella control in the water system of antiquated hospital buildings by shock and continuous hyperchlorination: 5 years experience. BMC Infect Dis 2014, 14:394.

34. Gałecki A, Burzykowski T: Linear Mixed-Effects Models Using R. New York, NY: Springer New York; 2013:542.

35. Pinheiro J, Bates D, DebRoy S, Sarkar D, R Core Team: nlme: Linear and Nonlinear Mixed Effects Models. 2014. Available at http://CRAN.R-project.org/ web/packages/nlme (Accessed 19/09/2014).

36. Lenth RV: Ismeans: Least-Squares Means. 2014. Available at http://CRAN.Rproject.org/lsmeans (Accessed 19/09/2014).

37. Lau HY, Ashbolt NJ: The role of biofilms and protozoa in Legionella pathogenesis: implications for drinking water. J Appl Microbiol 2009, 107:368-378.

38. Declerck P, Behets J, Margineanu A, Van Hoef V, De Keersmaecker B, Ollevier F: Replication of Legionella pneumophila in biofilms of water distribution pipes. Microbiol Res 2009, 164:593-603.

39. Cooper IR, Hanlon GW: Resistance of Legionella pneumophila serotype 1 biofilms to chlorine-based disinfection. J Hosp Infect 2010, 74:152-159.

40. Morton SC, Zhang Y, Edwards M: Implications of nutrient release from iron metal for microbial regrowth in water distribution systems. Water Res 2005, 39:2883-2892.

41. Lehtola MJ, Miettinen IT, Keinänen MM, Kekki TK, Laine O, Hirvonen A, Vartiainen T, Martikainen PJ: Microbiology, chemistry and biofilm development in a pilot drinking water distribution system with copper and plastic pipes. Water Res 2004, 38:3769-3779. 
42. Lehtola MJ, Miettinen IT, Lampola T, Hirvonen A, Vartiainen T, Martikainen PJ: Pipeline materials modify the effectiveness of disinfectants in drinking water distribution systems. Water Res 2005, 39:1962-1971.

43. Hallam NB, West JR, Forster CF, Powell JC, Spencer I: The decay of chlorine associated with the pipe wall in water distribution systems. Water Res 2002, 36:3479-3488.

44. Wingender J, Flemming $\mathrm{H}-\mathrm{C}$ : Biofilms in drinking water and their role as reservoir for pathogens. Int J Hyg Environ Health 2011, 214:417-423.

doi:10.1186/s12866-014-0249-8

Cite this article as: Solimini et al.: Factors influencing persistence of Legionella pneumophila serogroup 1 in laboratory cocultures. BMC Microbiology 2014 14:249.

\section{Submit your next manuscript to BioMed Central and take full advantage of:}

- Convenient online submission

- Thorough peer review

- No space constraints or color figure charges

- Immediate publication on acceptance

- Inclusion in PubMed, CAS, Scopus and Google Scholar

- Research which is freely available for redistribution 